\title{
Hélène Campaignolle-Catel, 'Mobile' (Butor, 1962), la carte fracturée du récit
}

\section{Elisa Bricco}

\section{(2) OpenEdition}

1 Journals

\section{Edizione digitale}

URL: http://journals.openedition.org/studifrancesi/33697

DOI: 10.4000/studifrancesi.33697

ISSN: 2421-5856

\section{Editore}

Rosenberg \& Sellier

\section{Edizione cartacea}

Data di pubblicazione: 1 décembre 2005

Paginazione: 679

ISSN: 0039-2944

\section{Notizia bibliografica digitale}

Elisa Bricco, «Hélène Campaignolle-Catel, 'Mobile' (Butor, 1962), la carte fracturée du récit», Studi Francesi [Online], 147 (XLX | III) | 2005, online dal 30 novembre 2015, consultato il 18 avril 2021. URL: http:// journals.openedition.org/studifrancesi/33697 ; DOI: https://doi.org/10.4000/studifrancesi.33697

Questo documento è stato generato automaticamente il 18 avril 2021.

\section{(c) $(1) \&$}

Studi Francesi è distribuita con Licenza Creative Commons Attribuzione - Non commerciale - Non opere derivate 4.0 Internazionale. 


\title{
Hélène Campaignolle-Catel, 'Mobile' (Butor, 1962), la carte fracturée du récit
}

\author{
Elisa Bricco
}

\section{NOTIZIA}

HÉLÈNE CAMPAIGNOLLE-CATEL, 'Mobile' (Butor, 1962), la carte fracturée du récit, «Littérature», 135, 2004, pp. 25-40.

1 Testo ai limiti della letterarietà e della leggibilità, Mobile appare oggi altamente moderno e addirittura precursore della scrittura frammentata e interattiva che trova largo spazio nella rete internet.

2 L'A. traccia un percorso di analisi approfondito e dettagliato delle componenti testuali e paratestuali del récit, mettendo in luce la dialettica che vi si instaura con l'arte di J. Pollock et di A. Calder. Il testo annuncia difatti un programma di lettura che indirizza il fruitore verso una percezione inedita della scrittura e dell'oggetto-libro. I concetti di discontinuo, frammentato, non-mimetico sono indispensabili chiavi di lettura per penetrare in Mobile, poiché Butor costruisce il suo récit scardinando le regole che sottendono alla scrittura e dunque, in un certo modo, costringe il lettore a seguirlo nella sua costruzione di inediti spazi testuali e di nuovi significati che appartengono più al labirinto che alla continuità. 